\title{
DETERMINAÇÃO DO PONTO DE COLHEITA DE FLORES DE Tropaeolum majus L.
}

\author{
Eliane Nunes da Silva ${ }^{1}$, Renata Ranielly Pedroza Cruz², Lylian Souto Ribeiro², Amadeu Pimentel \\ Travassos ${ }^{1}$, Christian Raphael Delfino Mouzinho Soares², Jean Flaviel de Sousa Meloํㅣㄹ Juciely \\ Gomes da Silva ${ }^{1}$, Wellington Souto Ribeiro ${ }^{3}$
}

\begin{abstract}
RESUMO - Tropaeolum majus L. é utilizada como flor comestível e medicinal. A conservação e a qualidade das flores são determinadas, principalmente, pelo estádio de maturação em que são colhidas. O objetivo deste trabalho foi determinar o ponto de colheita de flores de T. majus. Os estádios fenológicos das flores foram determinados visualmente. A antocianina, comprimento das flores, carotenoides, flavonoides, massa fresca e teor de sólidos solúveis aumentaram durante o desenvolvimento das flores seguido de uma redução nos estádios correspondentes a senescência. O teor de ácido ascórbico decresceu durante o desenvolvimento. O estádio XII corresponde ao ponto ideal de colheita para as flores de T. majus.
\end{abstract}

Palavras chave: fisiologia do desenvolvimento, potencial antioxidante, Tropaeolum majus L.

\section{DETERMINATION OF THE POINT OF HARVEST OF FLOWERS OF Tropaeolum majus $L$.}

\begin{abstract}
Tropaeolum majus L. is used as an edible and medicinal flower. The conservation and quality of the flowers are mainly determined by the maturity stage at which they are harvested. The objective of this work was to determine the harvest point of T. majus flowers. The phenological stages of the flowers were determined visually. Anthocyanin, flower length, carotenoids, flavonoids, fresh mass and soluble solids content increased during flower development followed by a reduction in the stages corresponding to senescence. The ascorbic acid content decreased during development. Stage XII corresponds to the ideal harvest point for T. majus flowers.
\end{abstract}

Keywords: developmental physiology, potential antioxidant, Tropaeolum majus L.

\section{INTRODUÇÃO}

O ciclo vital dos órgãos vegetais é composto por três fases fisiológicas, que correspondem ao crescimento, maturação e à senescência, embora não haja a possibilidade de uma distinção precisa entre elas. O desenvolvimento (formação, crescimento e maturação) das plantas e seus órgãos ocorrem seguindo uma série de processos fisiológicos e bioquímicos geneticamente programados, bem como, são influenciados por fatores ambientais (Chitarra \& Chitarra, 2005; Bloem et al., 2014).
O crescimento em plantas é definido como um aumento irreversível do tamanho ou volume celular acompanhado pela biossíntese de novos constituintes do protoplasma. O maior componente do crescimento vegetal é a expansão celular que é governada pela pressão de turgor (Taiz \& Zeiger, 2006). Durante este processo, as células aumentam várias vezes em volume e tornam-se altamente vacuoladas. Todavia, o tamanho é apenas um critério que pode ser usado para medir o crescimento. Assim, o crescimento pode ser medido, também, em termos de mudança do peso fresco, isto

\footnotetext{
${ }^{1}$ Sítio Imbaúba, s.n. Zona Rural Lagoa Seca-PB, 58117-000.Universidade Estadual da Paraíba, Campus II. lianbela2010@gmail.com; amadeutravassos@gmail.com; jeanifsm@gmail.com; jucielygomes07@hotmail.com; wellingtisouto@yahoo.com.br.2Rodovia PB-079, Areia-PB, 58397-000. Universidade Federal da Paraíba, Campus II. renataranielly426@gmail.com; agroph@gmail.com; lylian_sr97@hotmail.com.br. 3PH Rolfs s.n. Viçosa-MG, 36.570-900. Universidade Federal de Viçosa. wellingtisouto@yahoo.com.br.
} 
é, o peso do tecido vivo, durante um determinado período.

A diferenciação celular diz respeito às mudanças qualitativas nas células (Chitarra \& Chitarra, 2005). As variações nos fatores ambientais, como a luz, temperatura, precipitação pluviométrica, solo, entre outros, têm influência marcante na fase de desenvolvimento. Nos frutos, que são órgãos originados do crescimento das estruturas que formam as flores ou inflorescências, o início do crescimento é caracterizado por uma intensa divisão e pequena expansão celular, seguido de uma fase em que o processo de expansão é mais intenso, com grande acúmulo de água e solutos na polpa (Balbino \& Costa, 2003; Silva et al., 2013).

O amadurecimento, por sua vez, parece ser um processo coordenado de eventos bioquímicos e reorganizações metabólicas, sendo considerado um processo irreversível.

O amadurecimento é a fase mais estudada na póscolheita, principalmente por ser nessa fase que as mudanças de composição ocorrem com mais intensidade. De acordo com Bron (2006) e Burdon et al. (2016), o amadurecimento é a fase que ocorre no final do desenvolvimento e início da senescência, composta por processos que determinam as características de qualidade, evidenciadas por mudanças na composição, coloração, textura e outros atributos sensoriais. Nesse contexto, as mudanças físicas e físico-químicas durante o desenvolvimento e maturação dos órgãos vegetais são utilizadas como critérios importantes para determinar padrões de maturidade, ponto de colheita e qualidade.

O objetivo deste trabalho foi determinar o ponto de colheita de flores de T. majus a partir das transformações fisiológicas que ocorrem durante o seu desenvolvimento.

\section{MATERIAL E MÉTODOS}

\section{Caracterização da área de estudo}

As flores de Capuchinha foram obtidos de canteiro instalado no Centro de Ciências Agrárias da Universidade Federal da Paraíba (658'554" de latitude sul e 3543’047" de longitude oeste) com área total de $54 \mathrm{~m}^{2}$ dividido em 3 parcelas iguais de $18 \mathrm{~m}^{2}$. As mudas foram obtidas a partir de propagação vegetativa por estaquia de plantas matrizes oriundas do horto da UFPB. A temperatura média do período foi de $23,19 \pm 2{ }^{\circ} \mathrm{C}$, umidade relativa média de 83,19 \ 5\%, precipitação de 375 mm e insolação de 1907,1 horas ano ${ }^{-1}$.

\section{Determinação do ponto de colheita}

A determinação dos pontos de colheita seguiu a um padrão de crescimento e desenvolvimento préestabelecidos, onde as flores foram classificadas em quinze (15) estádios de desenvolvimento (Figura 1).

O estabelecimento dos estádios de maturação das flores foi estabelecido por observação diária das plantas, onde as primícias dos órgãos a serem utilizados nas avaliações foram marcadas com fita colorida para o acompanhamento de seu desenvolvimento e posterior colheita.

\section{Colheita}

As flores de T. majus foram colhidas manualmente sempre no período da manhã e transportados imediatamente a seco para o laboratório, onde foram rapidamente enxaguados em água destilada e secos em condições ambientais. Logo após, as flores foram caracterizadas quanto as suas características físicas e físico-químicas em todos os estádios de desenvolvimento pré-estabelecidos.

\section{Avaliações}

A caracterização física foi realizada em amostra de 50 unidades, avaliadas individualmente. Para as avaliações físico-químicas foram utilizados 100 órgãos homogeneizados em cadinho de porcelana, de onde foram retiradas 50 alíquotas para análise.

Massa fresca - Foi determinada individualmente em balança semianalítica MARK 31000 com precisão de $\pm 0,01 \mathrm{~g}$. Os resultados foram expressos em $\mathrm{g}$.

Diâmetro - Foram realizadas duas medições no sentido transversal (ST) e longitudinal (SL), com auxílio de um paquímetro universal com graduação de 0,02mm/.001" - 150mm/6".

Comprimento - O comprimento lateral das flores foi determinado com auxílio de régua. Os resultados de diâmetro e comprimento foram expressos em mm e cm, respectivamente.

Sólidos solúveis (SS) - O conteúdo de sólidos solúveis foi determinado no suco homogeneizado utilizando-se refratômetro digital (PR - 100, Palette, Atago Co. LTD., Japan) com compensação automática 


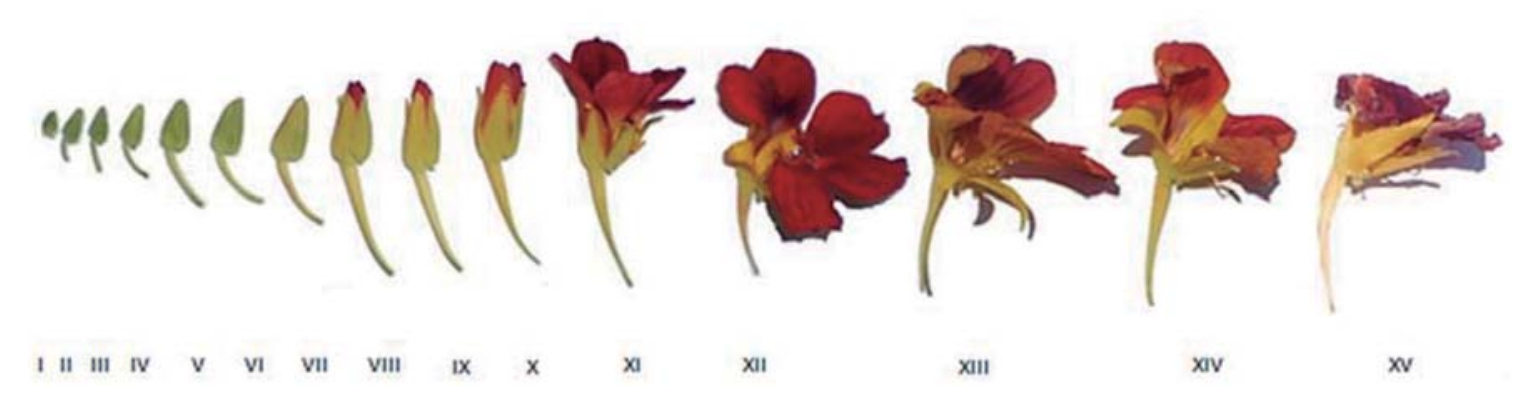

Figura 1 - Aspecto geral das flores de Tropaeolum majus L. durante os estádios de desenvolvimento. Fonte: Wellington Souto Ribeiro.

de temperatura. Os teores foram registrados com precisão de $0,1 \%$ a $25^{\circ} \mathrm{C}$ (KRAMER, 1973). Os resultados foram expressos em \%.

Acidez titulável (AT) - Foi determinada utilizando-se $1 \mathrm{~g}$ de material diluído em $50 \mathrm{ml}$ de água destilada submetida à titulação com $\mathrm{NaOH} 0,1 \mathrm{~N}$, com resultados expressos em \% de ácido cítrico (AOAC, 1994).

Ácido ascórbico - Foi determinado por titulometria utilizando-se solução de 2,6 diclofenolindofenol (DFI) a $0,02 \%$ até a obtenção de coloração róseo claro permanente, a partir de $1 \mathrm{~g}$ de material diluído em $30 \mathrm{ml}$ de ácido oxálico 0,5\% (Strohecker \& Henning, 1965).

Antocianinas - Analisadas exclusivamente nas flores por espectrofotometria em um comprimento de onda de $535 \mathrm{~nm}$, utilizando $1 \mathrm{~g}$ de material em solução extratora de etanol-HCL (1,5N) (Francis, 1982).

Flavonóides - Analisados exclusivamente nas flores por espectrofotometria em um comprimento de onda de $374 \mathrm{~nm}$, utilizando $1 \mathrm{~g}$ de material em solução extratora de etanol-HCL (1,5N) (Francis, 1982).

Carotenóides - Analisados exclusivamente nas flores por espectrofotometria em um comprimento de onda de 452nm, utilizando $1 \mathrm{~g}$ de material em solução extratora de acetona-hexano (Francis, 1982).

\section{Análise dos dados}

O experimento foi realizado em um delineamento inteiramente casualizado (DIC), com 50 repetições. Os dados obtidos foram avaliados através de estatística descritiva e os gráficos gerados pelo software SIGMA (Scientific data analysis and graphing software package).

\section{RESULTADOS E DISCUSSÃO}

A massa fresca das flores aumentou durante o desenvolvimento. No estádio I os valores médios de massa fresca foram de $0,07 \mathrm{~g}$, atingindo o seu máximo entre os estádios VIII e XII, com valores médios de 0,59 a 0,72 g, respectivamente. Um acréscimo de 10 vezes na massa fresca em relação ao peso inicial. No entanto, somente entre os estádios X e XII, as flores passaram por transformações que as tornaram mais comercialmente atrativas, caracterizada pela antese parcial a total. A partir desse ponto a massa fresca das flores apresentou diminuiu, resultante dos processos ordinários de senescência (Figura 2). O aumento da massa fresca durante o crescimento e desenvolvimento das flores está associado à expansão e divisão celular (Kawabata et al., 2011). A expansão celular é regulada pela acumulação osmótica, influxo de água e força das paredes celulares (Boyer et al., 1985; Cosgrove, 2001). Muitas proteínas e enzimas são necessárias para a expansão celular, incluindo a expansina, que está envolvido no afrouxamento da parede celular e cujos genes são expressos durante a abertura da flor de cravo (Cosgrove, 2000; Harada et al., 2011). Plantas de petúnia antisenso para o gene da expansina PhEXPA1 produzem flores menores pois as células são menores, enquanto a superexpressão do mesmo gene resulta em flores maiores como resultado de células maiores (Zenoni et al., 2004, 2011).

O comprimento médio das flores aumentou durante o desenvolvimento, variando de 0,91 a 5,76 cm, nos estádios I e XII, respectivamente (Figura 3). Este aumento se deve ao cálice pentâmero das flores de T. majus. As três sépalas inferiores apresentam-se concrescidas formando uma estrutura denominada 


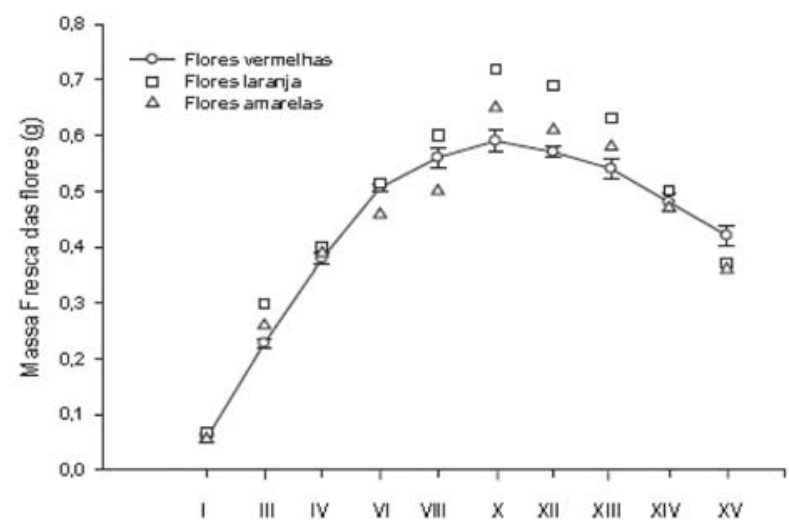

Figura 2 - Massa fresca de flores de T. majus durante o seu desenvolvimento.

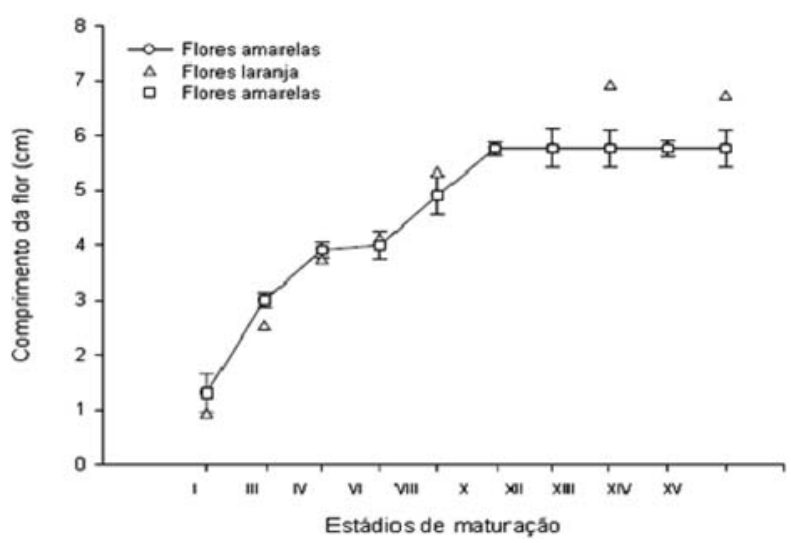

Figura 3 - Comprimento das flores de T. majus durante o seu desenvolvimento.

espora, com tecido nectarífero em seu interior (Castellani, 1997). O aumento ou crescimento da espora explica o aumento no comprimento das flores e pode ser utilizada como um parâmetro indicador das fases de crescimento até o ponto ideal de colheita das flores.

Os valores de sólidos solúveis variaram de 7,5 a 5,9\%, estádio I e VI, respectivamente. A partir do estádio VII, foi observada estabilização seguida de aumento no teor de sólidos solúveis, atingindo valores médios de 7,8\% no estádio de desenvolvimento considerado ótimo para comercialização (XII) (Figura 4). A redução do teor de sólidos solúveis se deve, provavelmente, a degradação dos polissacarídeos de reserva, como o amido, em compostos orgânicos mais simples (Kramer, 1973).

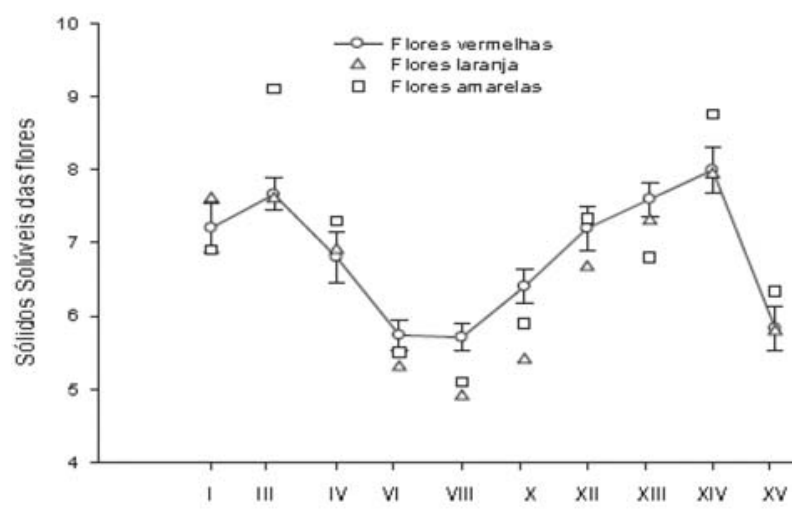

Figura 4 - Teor de sólidos solúveis em flores de T. majus durante o seu desenvolvimento.

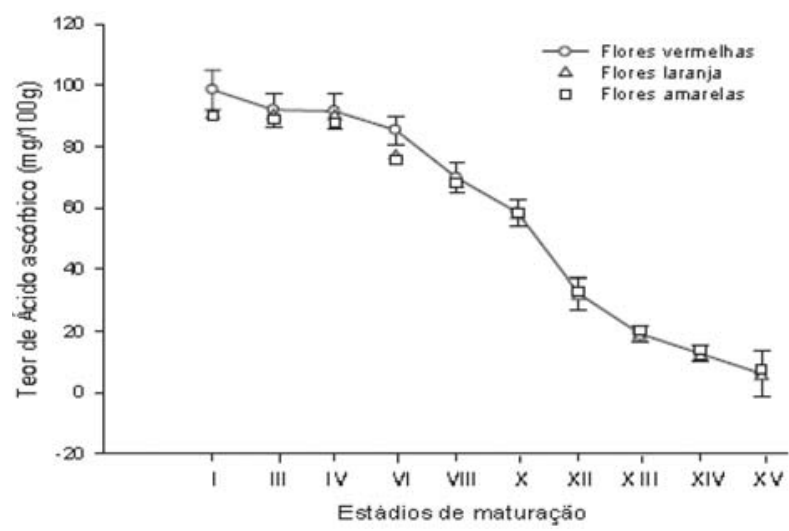

Figura 5 - Teor de ácido ascórbico em flores de T. majus durante o seu desenvolvimento.

Os teores médios de ácido ascórbico nas flores decresceram durante o desenvolvimento. O teor médio de ácido ascórbico encontrado no estádio I foi de 104,56 $\mathrm{mg} 100 \mathrm{~g}^{-1}$, atingindo teor médio de $18,42 \mathrm{mg} 100 \mathrm{~g}^{-1}$ no estádio XIV (Figura 5). Esta redução deve-se, presumivelmente, ao uso de ácidos orgânicos como substrato respiratório na via do ácido tricarboxílico (Weichmann, 1987) ou de sua conversão em açúcares (Chitarra \& Chitarra, 2005) ou ainda sua utilização como inibidor das espécies reativas de oxigênio (Conklin \& Barth, 2004) que são formados naturalmente durante a respiração. A molécula de ácido ascórbico desempenha funções metabólicas essenciais (Arrigoni \& de Tullio, 2002) no desenvolvimento vegetal, inclusive como cofator enzimático (Arrigoni \& de Tullio, 2000; de Tullio et al., 1999). 
O teor de carotenoides diferiu entre as cores das flores de $T$. majus. O teor máximo foi de 43,67, 26,45

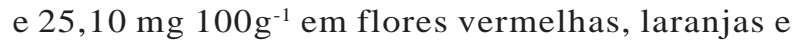
amarelas respectivamente (Figura 6A). O teor de flavonoides totais em flores de T. majus foi crescente durante o desenvolvimento, atingindo valores médios no estádio de maturação XII de 156,17 mg 100g${ }^{1}$ (Figura 6B). O teor de antocianinas aumentou durante o desenvolvimento das flores de T. majus (Figura 6C). A diferença entre o teor de carotenoides entre as flores de T. majus se deve a estrutura do tecido interno ou superficial de uma pétala e o tipo e quantidade de pigmentos nas células da pétala ( $\mathrm{Li}$ \& Yuan, 2013). Dentre os principais pigmentos presentes nas flores, os carotenoides e flavonoides têm importante papel na aceitação do produto pelo consumidor, pois a cor é uma característica importante da qualidade de frutas e vegetais e uma característica agronômica crítica para flores (Yuan et al., 2015). Portanto é um importante parâmetro para a escolha do ponto de colheita. Cores vivas são atribuídas a altos níveis de acumulação de carotenoides nos cromoplastos (Egea et al., 2010; Li \& Yuan, 2013). Os carotenoides são precursores de importantes fito hormônios, como o ácido abscísico e estrigolactonas, que são reguladores chave para o desenvolvimento de plantas (Walter \& Strack, 2011) o que pode estar relacionado com o aumento na sua concentração durante o desenvolvimento das flores de T. majus. As antocianinas são glicosídeos naturalmente formados por antocianidinas e vários açúcares (Zhao \& Tao, 2015). Eles estão estavelmente localizados nos órgãos da planta, como pétalas, e são vermelhos, roxos, azuis e pretos ( $\mathrm{Li}$ et al., 2003). As antocianinas são pigmentos vegetais responsáveis pela maioria das cores azul, roxa e todas as tonalidades de vermelho encontradas em flores, frutos, algumas folhas, caules e raízes de plantas (Dias et al., 2017). As antocianinas fazem parte do grupo dos flavonóides, compostos fenólicos caracterizados pelo núcleo básico flavílio. Além de contribuir para a cor de flores e frutas, as antocianinas atuam como filtro das radiações ultravioletas nas folhas. Em certas espécies de plantas estão associadas com a resistência aos patógenos e atuam melhorando e regulando a fotossíntese (Mazza \& Miniati, 1993).
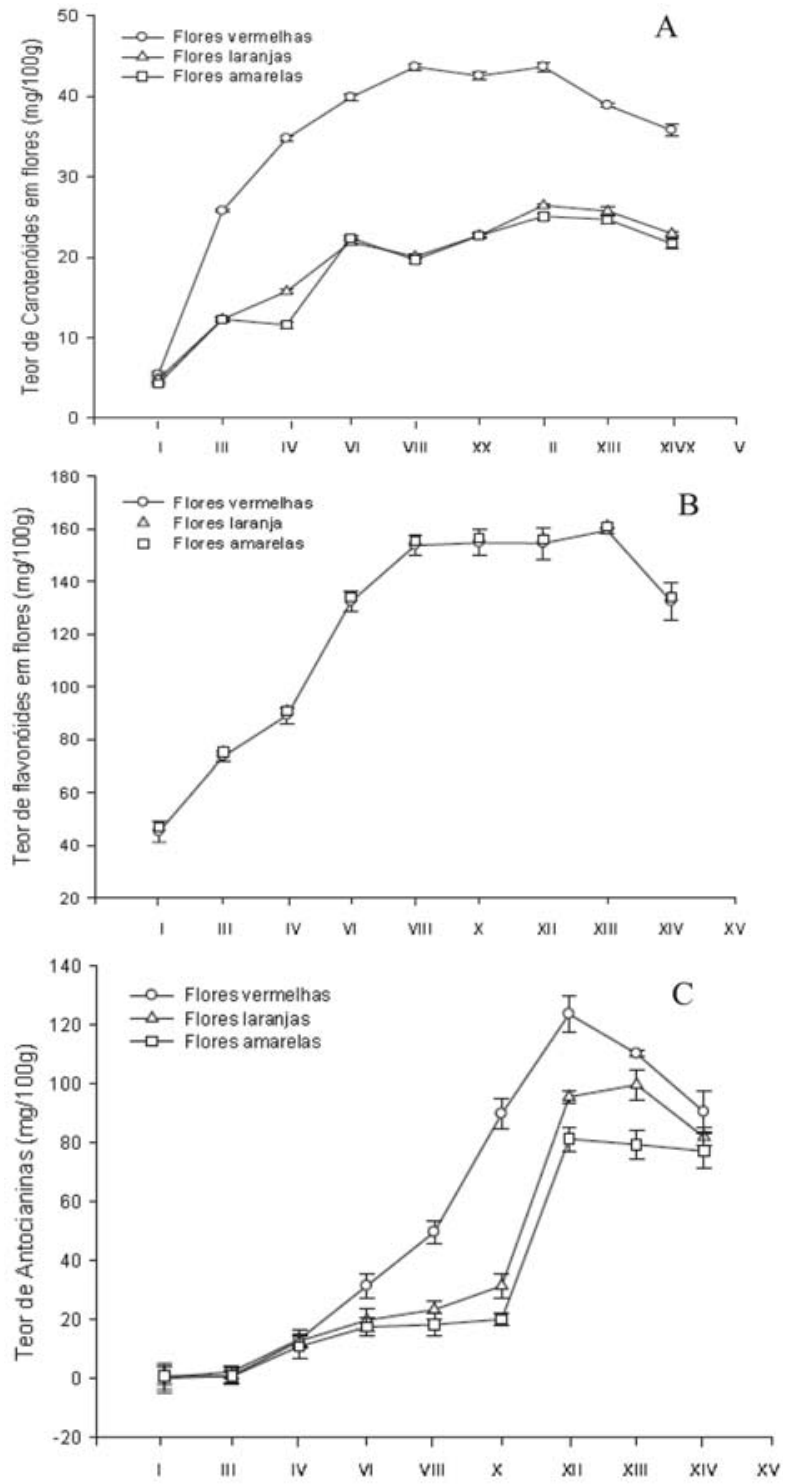

Figura 6 - Teor de carotenoides (A), flavonoides (B) e antocianinas (C) em flores de T. majus durante o seu desenvolvimento.

\section{CONCLUSÃO}

O ponto ideal de colheita para as flores de T. majus corresponde ao estádio de desenvolvimento XII.

\section{LITERATURACITADA}

ARRIGONI, O.; DE TULLIO, M.C. Ascorbic acid: much more than just an antioxidant. Biochimica et Biophysica Acta, v.1569, p.1-9, 2002. 
ARRIGONI, O.; DE TULLIO, M.C. The role of ascorbic acid in cell metabolism: between genedirected functions and unpredictable chemical reactions. Journal of Plant Physiology, v.157, p.481-488, 2000.

\section{ASSOCIATION OF OFFICIAL ANALYTICAL CHEMISTS. Official methods of analysis. 12.ed. Washington: AOAC, 1994. 1094p. \\ BALBINO, J.M.S.; COSTA, A.F.S. Crescimento e desenvolvimento dos frutos do mamoeiro do 'Grupo Solo' e padrão de qualidade. In: MARTINS, D.S.; BLOEM, E.; HANEKLAUS, S. et al. Stress-induced changes of bioactive compounds in Tropaeolum majus \\ L. Industrial Crops and Products, v.60, p.349-359, 2014.}

BOYER, J.S.; CAVALIERI, A.J.; SCHULZE, E.D. Control of the rate of cell enlargement: Excision, wall relaxation, and growth-induced water potentials. Planta, v.163, p.527-543, 1985.

BURDON, J.; PIDAKALA, P.; MARTIN, P. Fruit maturation and the soluble solids harvest index for 'Hayward' kiwi fruit. Scientia

Horticulturae, v.213, p.193-198, 2016.

CASTELLANI, D.C. Crescimento, anatomia e produção de ácido erúcico em Tropaeolum majus L. 108 f. Dissertação (Mestrado em Fitotecnia) Universidade Federal de Viçosa, Viçosa, 1997.

CHITARRA, M.I.F.; CHITARRA, A.B. Póscolheita de frutos e hortaliças: fisiologia e manuseio. 2.ed. Lavras: UFLA, 2005. 785p.

CONKLIN, P.L.; BARTH, C. Ascorbic acid, a familiar small molecule intertwined in the response of plants to ozone, pathogens, and the onset of senescence. Plant, Cell and Environment, v.27, p.959-971, 2004.

COSGROVE, D.J. Loosening of plant cell walls by expansins. Nature, v.407, p.321-326, 2000.

COSGROVE, D.J. Wall structure and wall loosening. A look backwards and forwards. Plant Physiology, v.125, p.131-134, 2001.
COSTA, A.F.S. (Eds). A cultura do mamoeiro: Tecnologias de Produção. Vitória: Incaper, 2003.

DE TULLIO, M.C.; PACIOLLA, C.; DALLA VECCHIA, F. et al. Changes in onion root development induced by the inhibition of peptidyl-proyl hydroxylase and influence of the ascorbate system on cell division and elongation. Planta, v.209, p.424-434, 1999.

DIAS, N.C.S.; MARQUES, K.F.; ALVES, M.C. et al. Caracterização química das antocianinas do fruto de juçara (Euterpe edulis

Martius). Revista Univap, v.22, p.703, 2017.

EGEA, I.; BARSAN, C.; BIAN, W.; PURGATTO, E. et al. Chromoplast differentiation: current status and perspectives. Plant Cell Physiology, v.51, p.1601-1611. 2010.

FRANCIS, F.J. Analysis of anthocyanins. In: MARKAKIS, P. Anthocyanins as food colors. London: Academic Press, 1982. p.181-206.

HARADA, T.; TORII, Y.; MORITA, S. et al. Cloning, characterization, and expression of xyloglucan endotransglycosylase/hydrolase and expansin genes associated with petal growth and development during carnation flower opening. Journal of Experimental Botany, v.62, p.815-823, 2011.

KAWABATA, S.; NII, K.; YOKOO, M. Threedimensional formation of corolla shapes in relation to the developmental distortion of petals in Eustoma grandiflorum. Scientia Horticulturae, v.132, p.66-70, 2011.

LI, L.; YUAN, H. Chromoplast biogenesis and carotenoid accumulation. Archives of Biochemistry and Biophysics, v.539, p.102-109, 2013.

LI, M.R.; CHEN, J.T.; SUN, Z.J. et al. Advances in molecular breeding of ornamental plants. Journal of Tropical and Subtropical Botany, v.11, p.87-92, 2003.

MAZZA, G.; MINIATI, E. Anthocyanins in fruits, vegetables and grains. Boca RatonFlorida (USA): CRC Press, 1993. 
SILVA, T.P.; LIMA, J.S.; CAVATTE, R.P.Q. et al. Physiology of flower development in Tropaeolum majus L. Acta Horticulturae, v.1002, p.193-198, 2013.

STROHECKER, R.; HENNING, H.M. Vitamin assay tested methods. Weinheim: Verlag Chemie, 1965. 360p.

TAIZ, L.; ZEIGER, E. Energy and Enzymes. Plant physiology. 4.ed. Sunderland: Sinauer Associates, 2006. cap.2, p.1-22.

WALTER, M.H., STRACK, D. Carotenoids and their cleavage products: biosynthesis and functions. Natural Product Reports, v.28, p.663-692, 2011.

WEICHMANN, J. Postharvest physiology of vegetables. New York: Marcel Dekker, 1987. 597p.
ZENONI, S.; FASOLI, M.; TORNIELLI, G.B. et al. Overexpression of PhEXPA1 increases cell size, modifies cell wall polymer composition and affects the timing of axillary meristem development in Petunia hybrida. New Phytologist, v.191, p.662-677, 2011.

ZENONI, S.; REALE, L.; TORNIELLI, G.B. et al. Down regulation of the Petunia hybrida áexpansin gene PhEXP1 reduces the amount of crystalline cellulose in cell walls and leads to phenotypic changes in petal limbs. The Plant Cell, v.16, p.295-308, 2004.

ZHAO, D.; TAO, J. Recent advances on the development and regulation of flower color in ornamental plants. Frontiers of Plant Science, v.6, p.261, 2015.

Recebido para publicação em 4/8/2017 e aprovado em 23/3/2018. 